\title{
Enhanced p62-NRF2 Feedback Loop due to Impaired Autophagic Flux Contributes to Arsenic-Induced Malignant Transformation of Human Keratinocytes
}

\author{
Xiafang Wu, ${ }^{1,2}$ Ru Sun, ${ }^{1}$ Huihui Wang, ${ }^{1}$ Bei Yang, ${ }^{3}$ Fang Wang, ${ }^{1}$ Hongtao Xu, ${ }^{3}$ \\ Shimin Chen, ${ }^{1}$ Rui Zhao, ${ }^{4}$ Jingbo Pi $\left({ }^{1},{ }^{1}\right.$ and Yuanyuan $\mathrm{Xu}\left(\mathbb{1}^{1}\right.$ \\ ${ }^{1}$ School of Public Health, China Medical University, China \\ ${ }^{2}$ The First Hospital of China Medical University, China \\ ${ }^{3}$ College of Basic Medical Sciences, China Medical University, China \\ ${ }^{4}$ School of Forensic Medicine, China Medical University, China
}

Correspondence should be addressed to Yuanyuan Xu; yyxu@cmu.edu.cn

Received 13 March 2019; Revised 16 August 2019; Accepted 29 August 2019; Published 30 October 2019

Academic Editor: Aldrin V. Gomes

Copyright (c) 2019 Xiafang Wu et al. This is an open access article distributed under the Creative Commons Attribution License, which permits unrestricted use, distribution, and reproduction in any medium, provided the original work is properly cited.

\begin{abstract}
Chronic exposure to arsenic induces a variety of cancers, particularly in the skin. Autophagy is a highly conserved process which plays a dual role in tumorigenesis. In the present study, we found that chronic exposure to an environmentally relevant dose of arsenite induced malignant transformation of human keratinocytes ( $\mathrm{HaCaT}$ ) with dysregulated autophagy as indicated by an increased number of autophagosomes, activation of mTORC1 pathway, and elevated protein levels of p62 and LC3II. Meanwhile, arsenite-transformed cells showed lower intracellular levels of reactive oxygen species compared with control. Silencing p62 ameliorated elevation in mRNA levels of NRF2 downstream genes (AKR1C1 and NQO1) and malignant phenotypes (acquired invasiveness and anchor-independent growth) induced by chronic arsenite exposure. On the other hand, silencing NRF2 abrogated the increase in mRNA and protein levels of p62 and malignant phenotypes induced by arsenite. In response to acute arsenite exposure, impaired autophagic flux with an increase in p62 protein level and interrupted autophagosome-lysosome fusion was observed. The increase in p62 protein levels in response to arsenite was not completely dependent on NRF2 activation and at least partially attributed to protein degradation. Our data indicate that accumulation of p62 by impaired autophagic flux is involved in the activation of NRF2 and contributes to skin tumorigenesis due to chronic arsenite exposure.
\end{abstract}

\section{Introduction}

Arsenic is a metalloid ubiquitously distributed in the environment. Chronic exposure to excessive levels of arsenic usually occurs through consumption of drinking water and contaminated food. Arsenic and arsenic compounds are identified as human carcinogens by the International Agency for Research on Cancer (IARC) [1]. Chronic exposure to arsenic induces a variety of cancers, particularly in the skin, lung, bladder, liver, and kidney [2]. However, the exact molecular mechanism of arsenic carcinogenicity is not well understood. The skin is one of the most sensitive tissues to chronic arsenic exposure. In humans, chronic exposure to arsenic results in various skin lesions, including hyperpigmentation, hyperkeratosis, and Bowen's disease, which are considered as precancerous lesions [3]. The characteristic arsenic-associated skin cancers include squamous cell carcinomas (SCCs) and basal cell carcinomas (BCCs) $[4,5]$.

Autophagy, an evolutionarily conserved cellular catabolic mechanism in eukaryotes, has vital roles in maintaining protein homeostasis and is essential to cell fate in response to stress [6]. Defects of autophagy lead to accumulation of dysfunctional organelles, damaged proteins, etc., which increase the risk of cancer $[7,8]$. On the other hand, autophagy facilitates drug resistance and stress adaptation of cancer cells [9]. Thus, it is considered that autophagy suppresses tumor 
formation and growth in the early stage of cancer but promotes cancer in the later stage. p62 acts as an autophagy receptor and is usually degraded after autophagy with the use of lysosomal proteases [10,11]. Elevated expression of p62 has been found in liver cancer, lung cancer, breast cancer, and skin cancer [1, 12-15]. Impaired autophagy resulting in p62 accumulation is reported to promote tumorigenesis [16]. Consistently, deficiency in $p 62$ diminishes chemicalinduced hepatocarcinogenesis in the mouse model [14]. In skin tumors, p62 is upregulated and promotes cell proliferation and migration by stabilizing the oncogenic factor TWSIT1 [15].

It is interesting that p62 is able to form a positive feedback loop with nuclear factor erythroid 2-related factor 2 (NRF2) [17], a key transcription factor in antioxidative defense [18]. Accumulation of p62 inhibits Keap1-mediated NRF2 protein degradation by competing with NRF2 for the binding site of Keap1, resulting in transcriptional upregulation of NRF2 downstream genes $[19,20]$. On the other hand, NRF2 regulates the expression of p62 by direct binding to the antioxidant response element on its promotor region. Our previous study has shown that NRF2 is constitutively activated in arsenic-transformed human keratinocytes ( $\mathrm{HaCaT}$ cells) [21]. Recently, chronic exposure to low levels of arsenite has been found to inhibit autophagy [22-25], which is attributed to overproduction of interleukin 6 [23]. Moreover, NRF2 activation in the scenario of low-level arsenic exposure is indicated to be dependent on p62 accumulation due to blockage of autophagic flux rather than reactive oxygen species (ROS) $[22,25,26]$. However, the role of this p62-NRF2 feedback loop in arsenic carcinogenesis has not been clearly identified.

In the present study, we found that arsenite-transformed human keratinocytes showed dysregulated autophagy with enhanced p62-NRF2 feedback loop and decreased intracellular ROS levels. Acute exposure to the environmentally relevant dose of arsenite blocked autophagic flux by interfering autophagosome-lysosome fusion, which contributed to the accumulation of p62. Silencing p62 or NRF2 ameliorated the arsenite-induced enhancement of p62-NRF2 feedback loop and furthermore the acquisition of malignant phenotypes. Our data suggest the important role of p62-NRF2 feedback loop in arsenite-induced skin tumorigenesis. This loop may be a target in prevention and therapy of arseniteinduced skin cancer.

\section{Results}

2.1. Chronic Exposure to an Environmentally Relevant Dose of Arsenite Induces Malignant Transformation and Dysregulated Autophagy in Human Keratinocytes. After a 30-week continuous arsenite exposure, $\mathrm{HaCaT}$ cells exhibited increased invasion capacity (Figure 1(a)) and anchorage-independent growth as illustrated by the formation of bigger colonies in soft agar (Figure 1(b)) compared with control (Con), all indicative of malignant transformation [27]. Thus, the 30-week arsenite-exposed cells were named as arsenite-transformed (As-TM) cells thereafter. Transmission electron microscopy (TEM) analysis of As-TM cells showed the massive accumu- lation of autophagosomes (Figures 1(c) and 1(d)), recognized as double-membrane vesicles engulfing cytosolic contents or organelles. The ratio of LC3II to LC3I (LC3II/I) and protein levels of p62 were markedly increased in As-TM cells compared with the control (Figure 1(e)). Upstream signaling pathways of autophagy, such as mTORC1 and BECN1, were also determined. The levels of phosphorylated mTOR (pmTOR) and phosphorylated P70S6K (p-P70S6K) were higher in As-TM cells than control (Figure 1(f)). No alteration was found in protein levels of BECN1 or RAPTOR in As-TM cells (Figure 1(f)). Collectively, these data indicate that chronic exposure to an environmentally relevant dose of arsenite induces malignant transformation of $\mathrm{HaCaT}$ cells with dysregulated autophagy.

2.2. Amplified p62-NRF2 Autoregulatory Loop Is Required for Arsenite-Induced Malignant Transformation of Human Keratinocytes. Arsenite is a well-known oxidative stressor [28]. However, in As-TM cells, intracellular ROS levels were only $50 \%$ of the control (Figures 2(a) and 2(b)). When cells were acutely challenged by a relatively high dose $(10 \mu \mathrm{M})$ of arsenite, intracellular ROS levels were increased to 2.8 -fold of Veh in control cells and 1.8-fold of Veh in As-TM cells, respectively (Figures 2(a) and 2(b)). The increase in ROS levels in As-TM cells was not as much as the control $(p<0.05)$ (Figures 2(a) and 2(b)). NRF2 and p62 were increased in both mRNA levels (Figure 2(c)) and protein levels (Figures 1(e) and 2(d)) in As-TM cells compared with the control $(p<0.05)$. This is consistent with our previous finding that NRF2 is activated in As-TM cells [21]. These results also indicate that adaptive antioxidative response instead of oxidative stress occurs in chronic arseniteexposed cells.

Amplified p62-NRF2 autoregulatory loop has been observed in several arsenic-exposed cells [22, 25]. However, the role of this loop in arsenic carcinogenesis is not fully defined. Thus, we silenced $p 62$ and NRF2, respectively, to determine whether suppression of this loop affects arsenicinduced malignant transformation. Successful knockdown of p62 was verified at mRNA and protein levels (Figures 3(a) and $3(\mathrm{~b})$ ). The protein expression of NRF2 in total cell lysis, as well as downstream genes of NRF2, AKR1C1, and NQO1, was significantly suppressed by $p 62$ silencing in arsenite-exposed cells (Figures 3(b) and 3(c)). Effective $N R F 2$ silencing was verified by mRNA levels of itself and its downstream genes (Figure 3(d)). Silencing NRF2 abolished arsenite-induced upregulation of p62 in both mRNA and protein levels (Figure 3(e)). Moreover, when cells with silenced NRF2 or $p 62$ were exposed to arsenite for 30 weeks, the invasion capacity (Figure 3(f)) and colony-forming ability (Figure 3(g)) were significantly decreased compared with scramble.

2.3. Arsenite Exposure Blocks Autophagic Flux by Interfering Autophagosome-Lysosome Fusion. Amplified p62-NRF2 autoregulatory loop can be attributed to impaired autophagy flux [22]. To further investigate the specific alteration of autophagy in response to arsenite, $\mathrm{HaCaT}$ cells were treated with arsenite at the concentrations of $100 \mathrm{nM}$ or $200 \mathrm{nM}$ for 


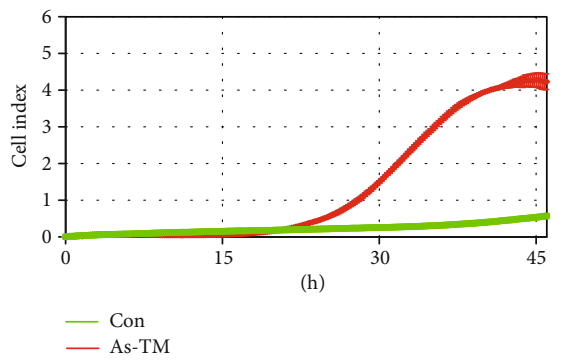

(a)
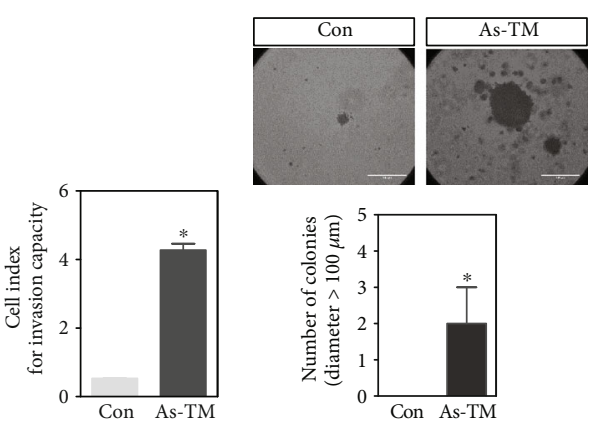

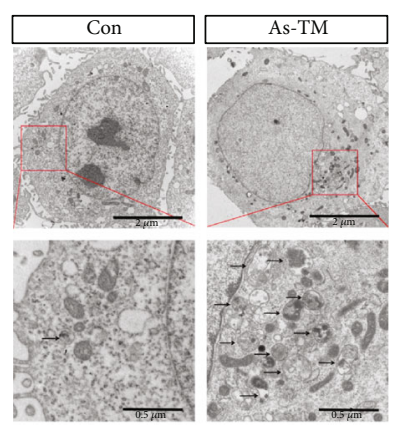

(c)

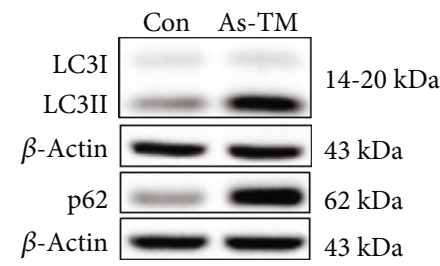

(b)

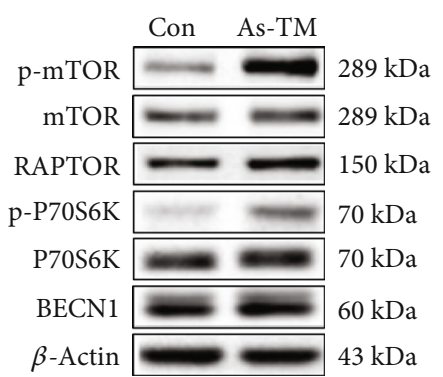

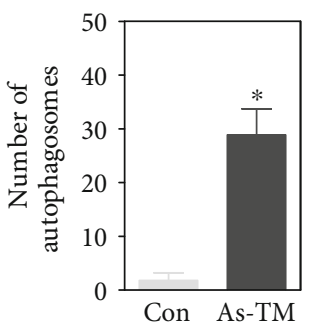

(d)

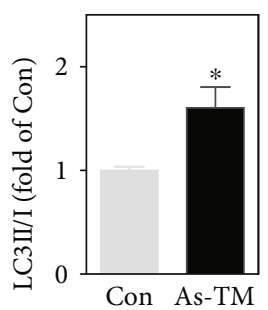

(e)

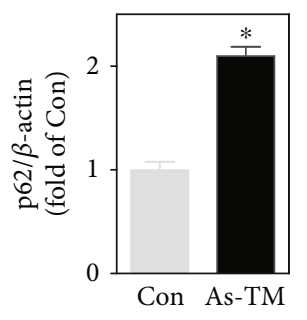

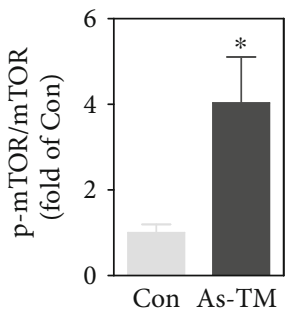

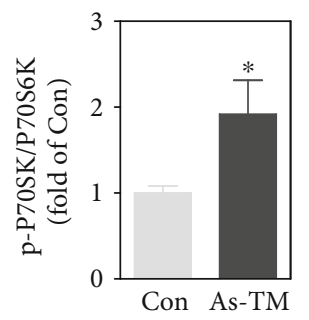

(f)

FIgURE 1: Alterations of autophagy markers and upstream signaling pathways in arsenite-transformed (As-TM) cells. HaCaT cells were treated with $100 \mathrm{nM}$ of sodium arsenite (As) for 30 weeks. Passage-matched nontreated cells were used as the control (Con). (a) Cell invasion analyzed with real-time cell analysis (RTCA) xCELLigence system. The left chart shows the kinetic analysis of cell invasion. The right panel shows the average index reflecting cell invasion capacity at $45 \mathrm{~h}$. (b) Colony formation in soft agar. Representative images of the control (upper left panel), As-TM cells (upper right panel), and quantification of colonies (lower panel) are shown. Scale bar is $100 \mu \mathrm{m}$. For quantification, three fields of view were randomly selected from each $35 \mathrm{~mm}$ culture dish. The number of clones with a diameter greater than $100 \mu \mathrm{m}$ was counted. (c) Increase in number of autophagosomes in As-TM cells. Autophagosomes were observed with transmission electron microscopy (TEM). Scale bar is $2 \mu \mathrm{m}$ (up) and $0.5 \mu \mathrm{m}$ (down). Arrows indicate autophagosomes. (d) Number of autophagosomes per cell according to TEM. (e) Western blot for autophagy markers, LC3 and p62. Upper: representative image; lower: quantification of protein levels of LC3II/I and p62 determined with Western blot. (f) Western blot for BECN1 and proteins in the mTORC1 pathway, including p-mTOR, mTOR, RAPTOR, p-P70S6K, and P70S6K. Upper: representative image; lower: quantification of $\mathrm{p}-\mathrm{mTOR} / \mathrm{mTOR}$ and $\mathrm{p}$-P70S6K/P70S6K determined with Western blot. $n=3$ except for colony formation, in which $n=6 .{ }^{*} p<0.05$, compared with Con.

$6 \mathrm{~h}$. Consistent with the results in As-TM cells, accumulation of autolysosomes in arsenite-treated cells was observed (Figures 4(a) and 4(b)). Though arsenite led to a concentration-dependent increase in LC3II/I and p62 protein levels within $200 \mathrm{nM}$ at $6 \mathrm{~h}, 500 \mathrm{nM}$ arsenite did not show such an effect (Figure 4(c)). In the time-course analysis, protein levels of LC3II/I and p62 were significantly increased in cells treated with $100 \mathrm{nM}$ of arsenite after $3 \mathrm{~h}$ (Figure $4(\mathrm{~d})$ ). Accumulation of p62 is an indicator for defects in autophagic degradation $[29,30]$. To assess how arsenite interferes with autophagic flux, lysosomal protease inhibitor chloroquine (CQ) was used. The protein levels of p62 were not significantly changed in cells treated with CQ plus arsenite compared to cells treated with CQ alone (Figure 4(e)). These results indicate that the accumulation of $\mathrm{p} 62$ induced by arsenite is due to the blockage of autophagosome degradation.

We next compared the location of a tandem mouse red/green fluorescent protein- (mRFP-) GFP-LC3 signals to the lysosome, to determine whether arsenite impaired autophagosome-lysosome fusion. HaCaT cells transfected 


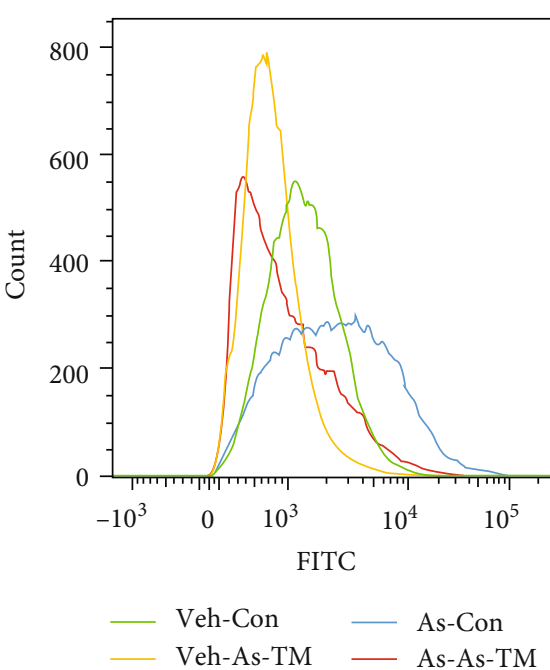

(a)

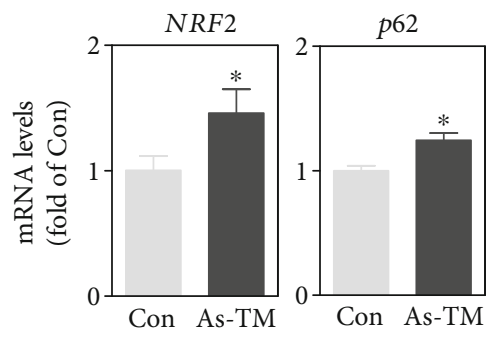

(c)

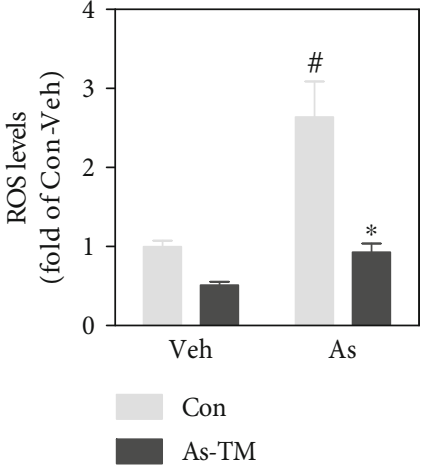

(b)

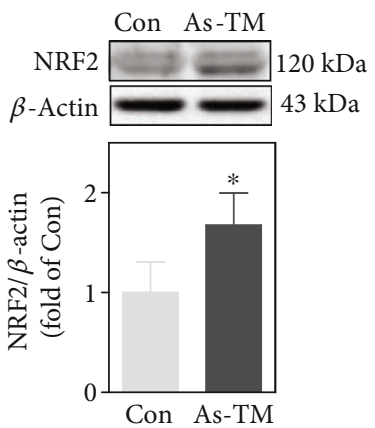

(d)

FIgURE 2: Long-term exposure to low-level arsenite induced adaptive antioxidative response in HaCaT cells. (a) Representative histogram for intracellular ROS levels detected by flow cytometer. As-TM cells or passage-matched nontreated control (Con) was challenged with $10 \mu \mathrm{M}$ of sodium arsenite (As) or equal volume of PBS (Veh) for $24 \mathrm{~h}$. (b) Quantification of intracellular ROS levels determined by flow cytometer. (c) mRNA levels of NRF2 and p62 in As-TM and control cells. (d) Western blot of NRF2 in As-TM and control cells. Upper: representative image; lower: quantification of NRF2 protein levels determined with Western blot. $n=3 .{ }^{*} p<0.05$, compared with Con compartment. ${ }^{\#} p<0.05$, compared with Veh compartment.

with mRFP-GFP-LC3 showed yellow/orange puncta due to CQ treatment (Figures $4(\mathrm{f})$ and $4(\mathrm{~g})$ ), which is known to inhibit autophagosome-lysosome fusion [31]. We found similar results in cells exposed to arsenite for $4 \mathrm{~h}$ with varying degrees of yellow/orange convergence (Figures $4(\mathrm{f})$ and $4(\mathrm{~g})$ ), indicating that arsenite impairs autophagic flux by preventing the fusion of autophagosomes and lysosomes. Lysosome-associated membrane protein (LAMP) 1 and LAMP2 are major protein components of the lysosomal membrane, which mediate a number of essential functions of this compartment [32]. A concentration (100 nM to $500 \mathrm{nM}$ at $6 \mathrm{~h}$ )- and time (100nM within $12 \mathrm{~h}$ )- dependent reduction in protein levels of LAMP1 and LAMP2 in response to arsenite was observed (Figures $4(\mathrm{~g})$ and $4(\mathrm{~h})$, respectively).

2.4. P62 Overexpression Induced by Environmentally Relevant Dose of Arsenite Is Attributed to Enhanced Transcription and Reduced Protein Degradation. Arsenite has been shown to activate NRF2, which transcriptionally regulates p62 expression. No alteration was found in NRF2 protein expression in total cell lysis at $6 \mathrm{~h}$ with $100 \mathrm{nM}$ of arsenite exposure, while p62 protein levels were increased (Figure 5(a)). Analysis of NRF2 downstream genes showed that mRNA levels of $p 62$ were significantly increased at $6 \mathrm{~h}$, but mRNA levels of NQO1 and GCLC were upregulated at $12 \mathrm{~h}$ (Figure 5(b)). NRF2 silencing suppressed arsenite-induced p62 overexpression (Figure 5(a)). As expected, arsenite, even at such a low nontoxic level, induces NRF2 activation which contributes to increased p62 protein levels. Further, we assessed the effect of arsenite on p62 turnover. As shown in Figure 5(c), inhibition of protein synthesis by cycloheximide (CHX) decreased p62 protein levels. Under such a condition, arsenite treatment significantly attenuated decrease of $\mathrm{p} 62$ protein levels (Figure 5(c)), indicating that the inhibition of protein degradation contributes to $\mathrm{p} 62$ accumulation by arsenite.

\section{Materials and Methods}

3.1. Cell Culture and Arsenite Exposure. HaCaT human keratinocytes (N.E. Fusening, German Cancer Research 


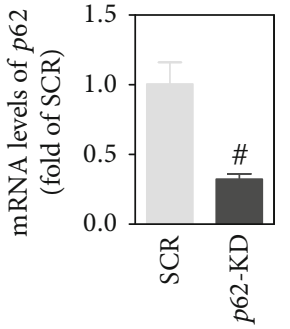

(a)

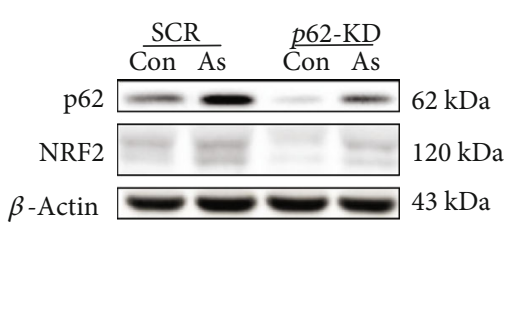

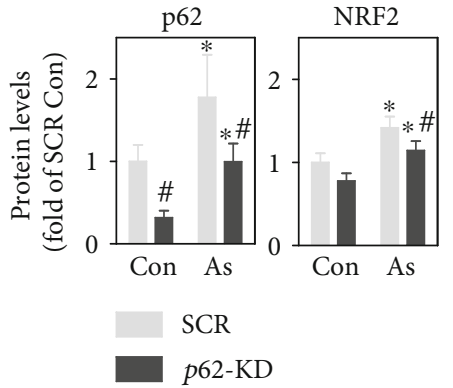

(b)

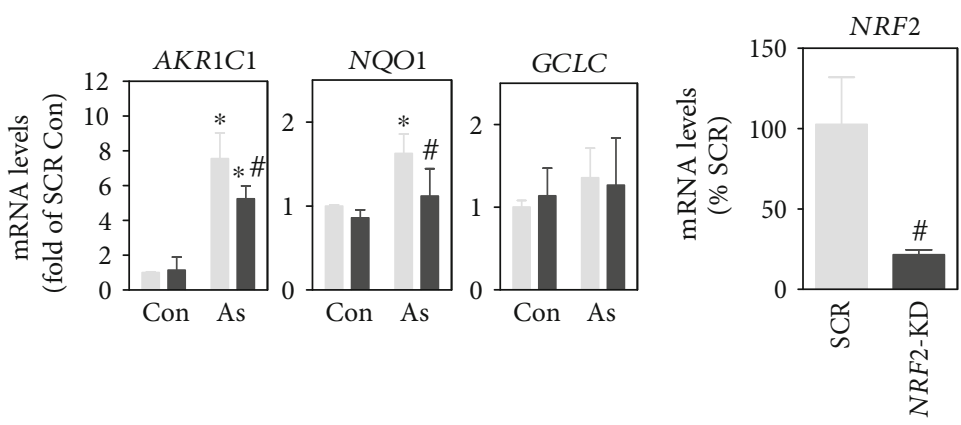

(c)
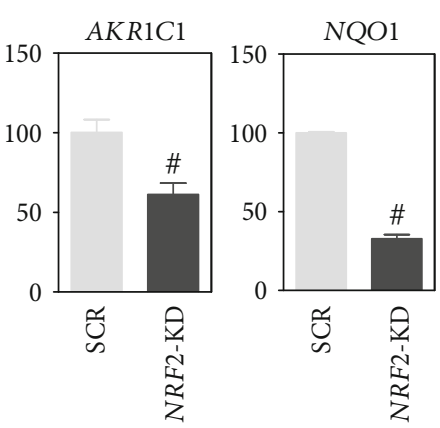

(d)
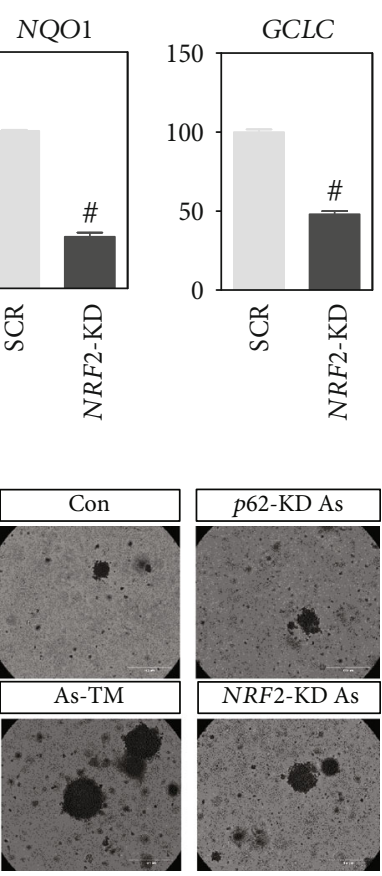

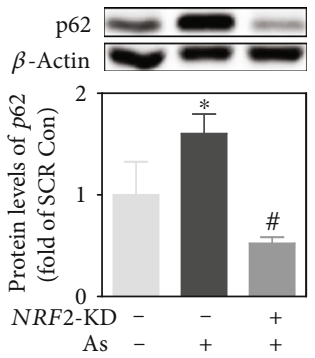

(e)
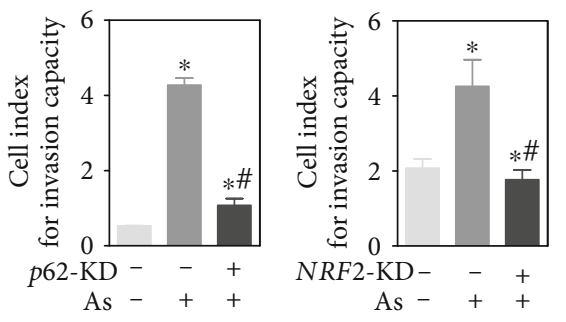

(f)

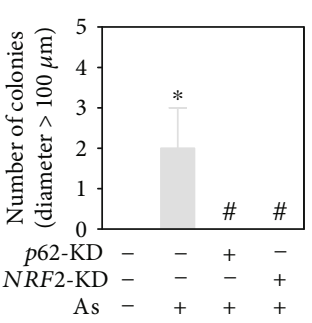

(g)

FIGURE 3: Amplification of p62-NRF2 feedback loop is required for the acquisition of arsenite-induced malignant phenotypes. (a) mRNA levels of p62 in HaCaT cells infected with lentiviral vector expressing shRNA targeting p62 (p62-KD) or scrambled nontarget negative control (SCR). (b) Protein levels of p62 and NRF2 in p62-KD and SCR cells. Left: representative image; right: quantification of protein levels of p62 and NRF2 determined with Western blot. (c) mRNA levels of NRF2 downstream genes, AKR1C1, GCLC, and NQO1, in p62KD and SCR cells. (d) mRNA levels of NRF2 and its downstream genes in chronic arsenite-exposed cells with NRF2 knockdown (NRF2KD). (e) mRNA and protein levels of p62 in NRF2-KD cells analyzed with RT-PCR (left) and Western blot (right), respectively. Upper right: representative image for Western blot; lower right: quantification of p62 protein levels determined with Western blot. (f) Invasion capacity determined by xCELLigence RTCA. Cell index at $45 \mathrm{~h}$ after seeding was used to assess invasion capacity. (g) Colony formation in soft agar. Representative image (upper) and quantification of the colonies (lower). Scale bar is $100 \mu \mathrm{m}$. As (As+): cells were chronically exposed to $100 \mathrm{nM}$ of sodium arsenite for 30 weeks. Con: passage-matched nontreated cells. $n=3$ except for colony formation assay, in which $n=6$. ${ }^{*} p<0.05$, compared with control (As-) compartment. ${ }^{*} p<0.05$, compared with SCR (NRF2-KD- or $p 62-\mathrm{KD}$-) compartment.

Center, Heidelberg, Germany) were cultured in Dulbecco's modified Eagle's medium (DMEM) (Thermo Fisher Scientific, Beijing, China) supplemented with $10 \%$ fetal bovine serum (FBS) (Biological Industries (BI), Hazafon, Israel) and $1 \%$ penicillin-streptomycin solution (BI) at $37^{\circ} \mathrm{C}$ in a humidified $5 \% \mathrm{CO}_{2}$ atmosphere. Cells at $80 \%$ confluence 


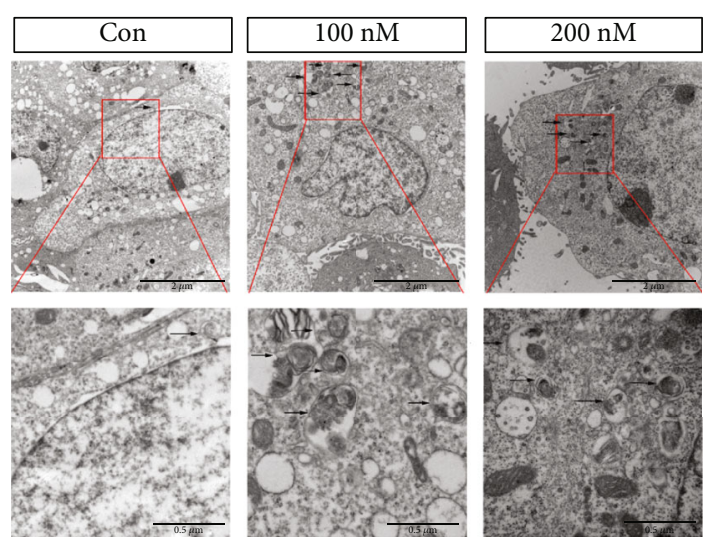

(a)

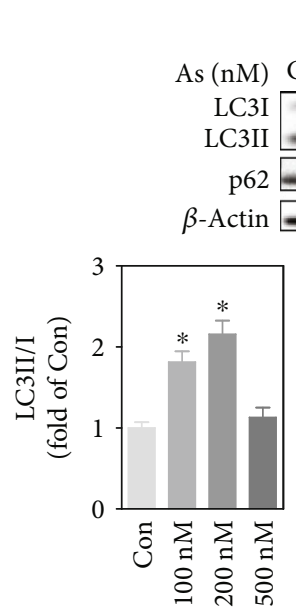

$\frac{6 \mathrm{~h}}{100 \quad 200 \quad 500}$

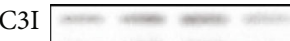

LC3II $\longrightarrow$

$\mathrm{p} 62$
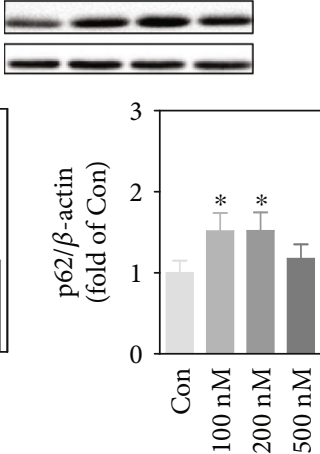

(c)

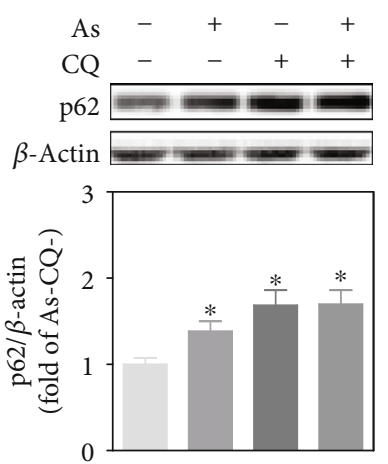

(e)

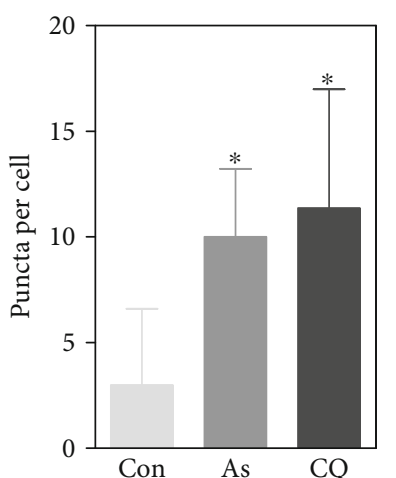

(f)

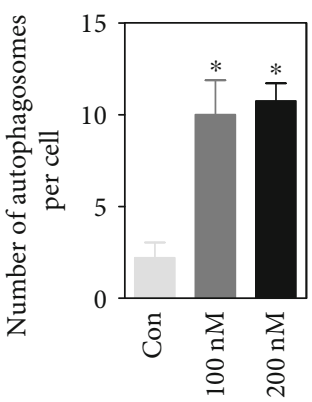

(b)
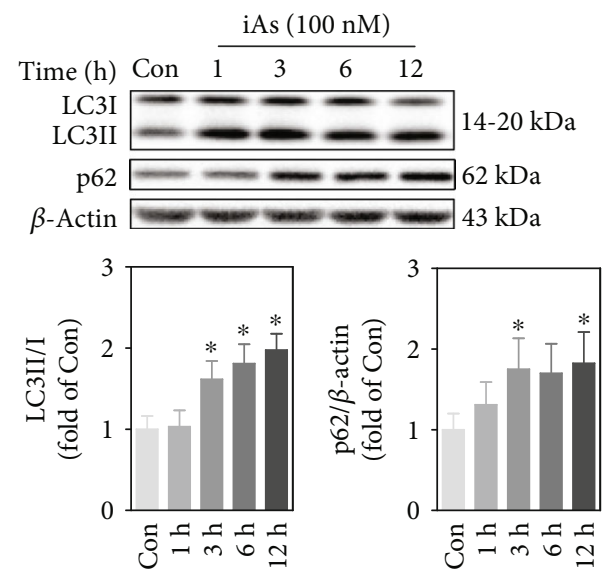

(d)
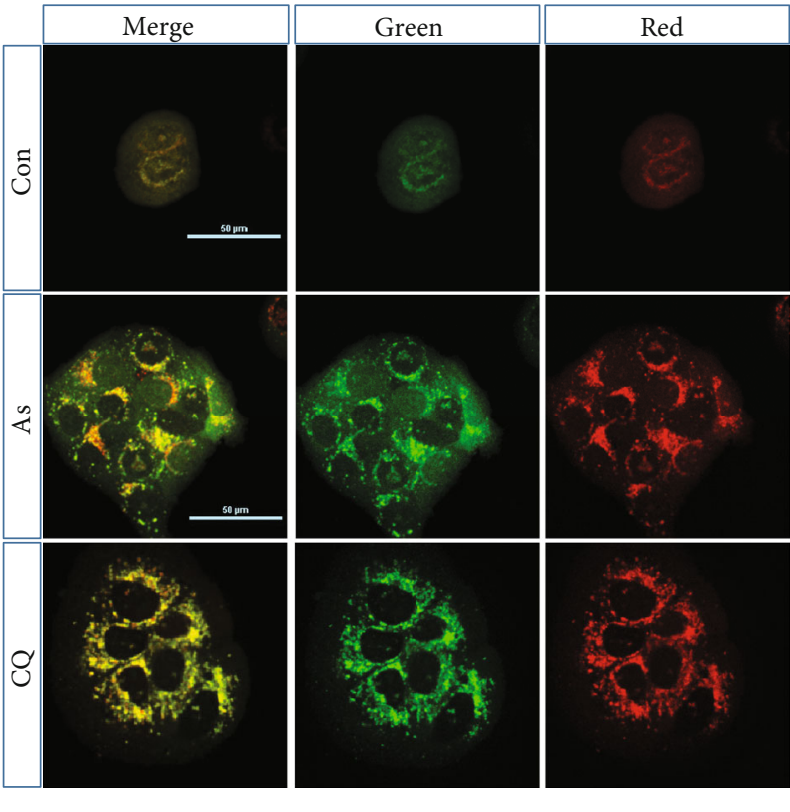

(g)

Figure 4: Continued. 


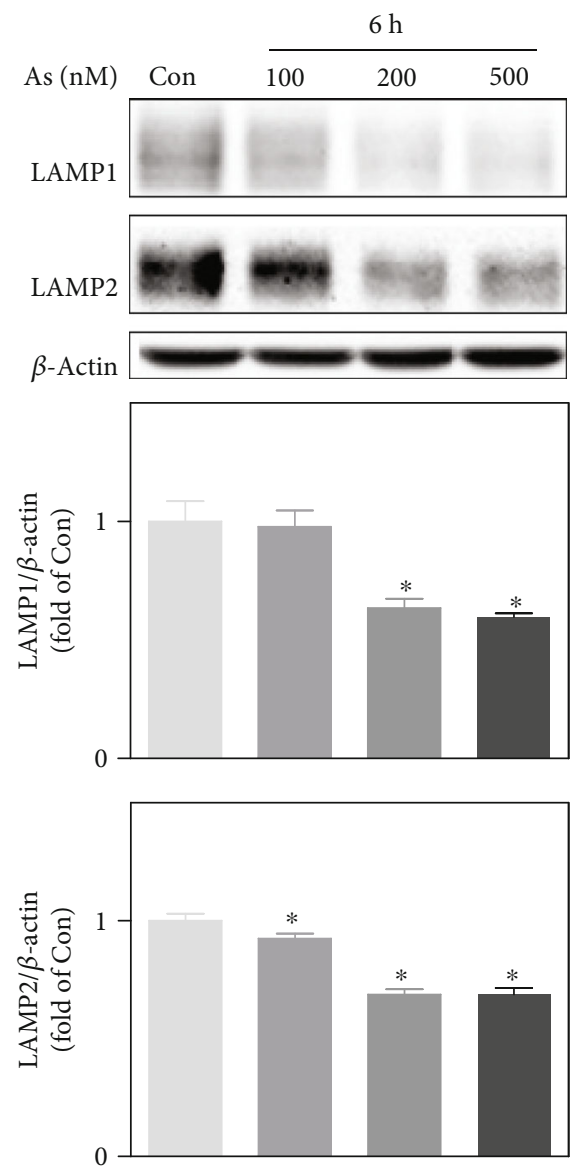

(h)

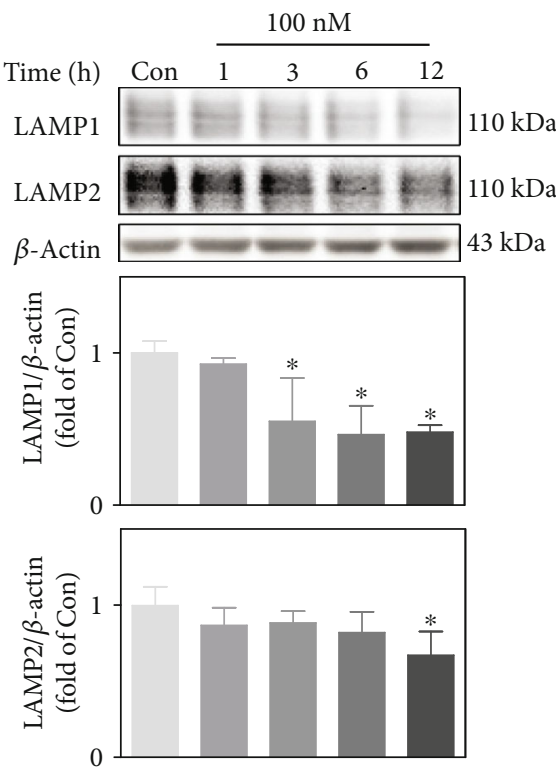

(i)

FIGURE 4: Arsenite inhibits autophagosome-lysosome fusion. (a) Autophagosomes observed with TEM in cells nontreated (Con) or treated with $100 \mathrm{nM}$ or $200 \mathrm{nM}$ sodium arsenite for $4 \mathrm{~h}$. Arrows indicate autophagosomes. Scale bar is $2 \mu \mathrm{m}$ (up) and $0.5 \mu \mathrm{m}$ (down). (b) Number of autophagosomes per cell according to TEM. (c) Western blot for LC3 and p62 in HaCaT cells treated with $100 \mathrm{nM}, 200 \mathrm{nM}$, or $500 \mathrm{nM}$ arsenite for $6 \mathrm{~h}$. (d) Western blot for LC3 and p62 in HaCaT cells treated with $100 \mathrm{nM}$ arsenite at different time points. (e) Protein levels of p62 detected with Western blot. Arsenite-induced inhibition of autophagic flux was tested with chloroquine $(\mathrm{CQ}, 30 \mu \mathrm{M})$ pretreatment and in the absence (-) or presence (+) of $100 \mathrm{nM}$ arsenite for $6 \mathrm{~h}$. (f) Quantification of orange/yellow LC3 puncta in the cell. HaCaT cells were transfected with a tandem mRFP-GFP-LC3 and then treated with $100 \mathrm{nM}$ arsenite for $4 \mathrm{~h}$ or $30 \mu \mathrm{M}$ CQ for $6 \mathrm{~h}$. The number of puncta in cells was counted using ImageJ software. Average number of orange/yellow puncta per cell from 16 randomly selected cells in each group was shown. (g) Representative image of LC3 fluorescence observed by a confocal microscope. Scale bar is $50 \mu \mathrm{m}$. (h) Western blot for LAMP1 and LAMP2 in HaCaT cells treated with $100 \mathrm{nM}, 200 \mathrm{nM}$, or $500 \mathrm{nM}$ arsenite for $6 \mathrm{~h}$. (i) Western blot for LAMP1 and LAMP2 in HaCaT cells exposed to $100 \mathrm{nM}$ arsenite at different time points. For Western blot, upper: representative image; lower: quantification of protein levels determined with Western blot. $n=3 .{ }^{*} p<0.05$, compared with Con (or As- and CQ-).

were passaged according to $1: 5$ proportion. The culture medium was refreshed every 2 days. For chronic arsenite exposure, $\mathrm{HaCaT}$ cells were maintained continuously in a medium containing $100 \mathrm{nM}$ of sodium arsenite $\left(\mathrm{NaAsO}_{2}\right)$ (Sigma-Aldrich, St. Louis, USA) for 30 weeks. Passagematched nontreated cells were used as the control. This arsenite concentration is comparable to the blood arsenite level of chronic arsenicosis patients [21,33].

3.2. Lentiviral-Based shRNA Transduction. Transduction of $\mathrm{HaCaT}$ cells with lentiviral-based shRNAs targeting NRF2 (SHVRS-NM 010902, Sigma-Aldrich), p62 (GeneChem, Shanghai, China), or scrambled nontarget negative control was performed as described previously [34, 35]. The selection media for $\mathrm{HaCaT}$ cells contained $1 \mu \mathrm{g} / \mathrm{mL}$ of puromycin (Thermo Fisher Scientific).
3.3. Kinetics of Cell Invasion. A cell invasion test was performed on the RTCA xCELLigence system (ACEA Biosciences Inc., CA, USA) equipped with a CIM-plate 16 . The plate is composed of upper and lower chambers separated by a microporous metallic membrane with a thin layer of Matrigel basement membrane. In each well, $4 \times 10^{4}$ cells were added in the upper chamber. The xCELLigence system based on electrical impedance measurement allows for the dynamic monitoring [36]. Electronic signals at the lower chamber as invasion cell indexes were monitored every min for up to $50 \mathrm{~h}$. The cell index was calculated as follows: (impedance at time point $n$-impedance in the absence of cells)/nominal impedance value [36].

3.4. Colony Formation in Soft Agar. We used a colony formation assay to assess anchorage-independent growth. $2 \mathrm{~mL}$ of 

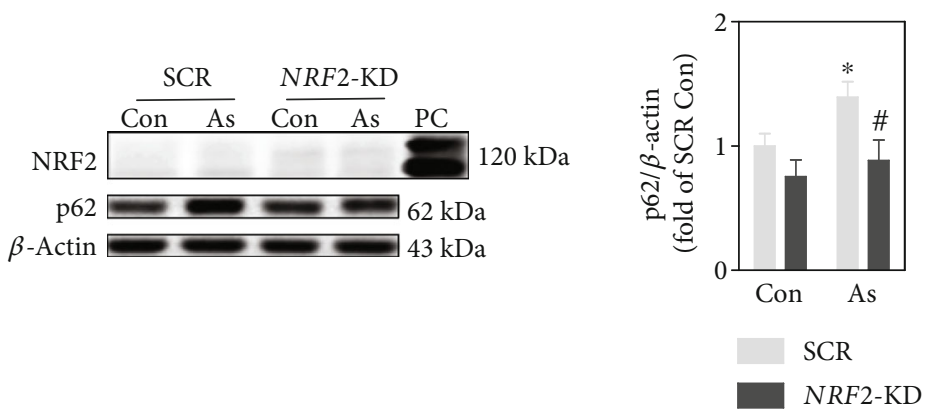

(a)
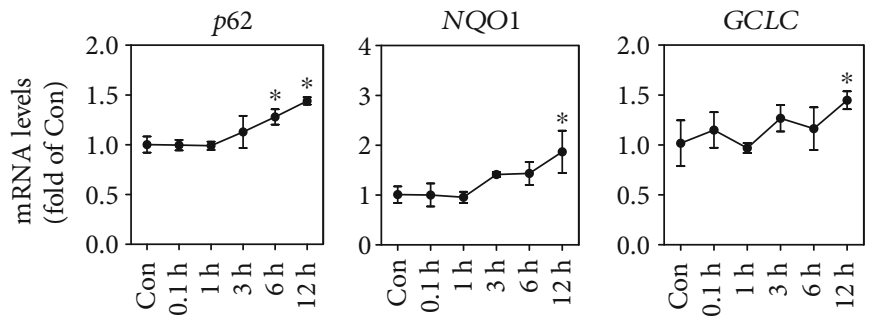

(b)
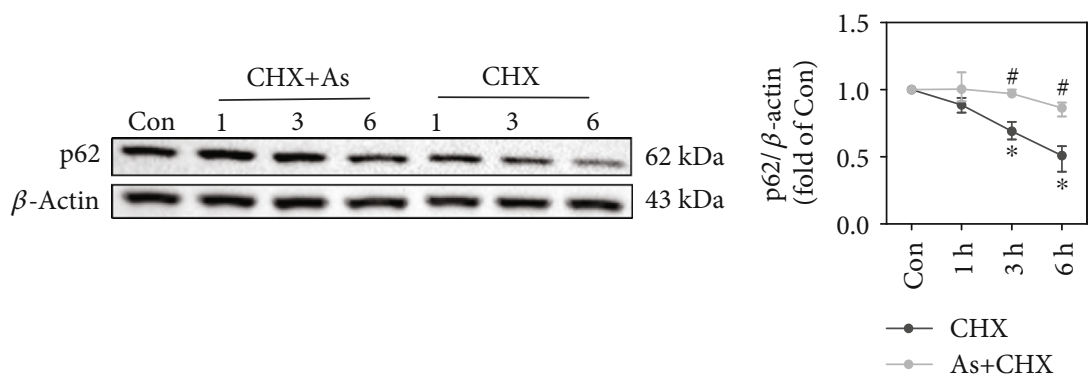

(c)

FIGURE 5: Enhanced transcription and decreased protein turnover contribute to accumulation of p62 protein in response to arsenite exposure. (a) Western blot of NRF2 and p62 under basal and arsenite-treated conditions in SCR and NRF2-KD cells. As: cells were treated with 100 nM sodium arsenite for $6 \mathrm{~h}$. PC: positive control, cells were treated with $20 \mu \mathrm{M}$ sodium arsenite for $6 \mathrm{~h}$. (b) mRNA levels of p62, NQO1, and GCLC in $\mathrm{HaCaT}$ cells treated with $100 \mathrm{nM}$ sodium arsenite at different time points. (c) Exposure to arsenite inhibited p62 degradation in HaCaT cells. Cells were treated with $\mathrm{CHX}(10 \mu \mathrm{g} / \mathrm{mL})$ or $\mathrm{CHX}+\mathrm{As}(100 \mathrm{nM})$ at different time points, followed by Western blot analysis. For Western blot, left: representative image; right: quantification of p62 protein levels. $n=3 .{ }^{*} p<0.05$, compared with Con compartment. ${ }^{*} p<0.05$, compared with SCR compartment or CHX-treated compartment.

$0.5 \%$ agar (Sigma-Aldrich) in complete growth media was used to cover the bottom of each $35 \mathrm{~mm}$ dish. $1.25 \times 10^{4}$ cells suspended with $1 \mathrm{~mL}$ of $0.33 \%$ agar in complete growth media were overlaid onto base agar. Cells in agar medium were cultured in a $\mathrm{CO}_{2}$ incubator. The colonies were identified with iodonitrotetrazolium chloride (INT) (SigmaAldrich) staining after a 4-week incubation.

3.5. Transmission Electron Microscopy. Cell pellets were fixed in $2.5 \%$ glutaraldehyde solution (Sigma-Aldrich) in $0.1 \mathrm{M}$ phosphate buffer for $24 \mathrm{~h}$ at $4^{\circ} \mathrm{C}$, dehydrated using a gradient series of ethanol, and infiltrated with Epon 812 (Structure Probe, Inc., West Chester, USA). Finally, the specimens were cut into $1 \mu \mathrm{m}$ sections with LKB-V ultramicrotome (Bromma, Stockholm, Sweden) and stained with uranyl acetate and lead citrate. Sections were examined using a transmission electron microscope (Hitachi, Tokyo, Japan).
3.6. Reverse Transcriptase Quantitative Polymerase Chain Reaction (RT-qPCR). RT-qPCR was conducted as previously described [37]. Total RNA was isolated using a TRIzol reagent (Thermo Fisher Scientific) and reverse transcribed to cDNA with a Prime Script RT reagent Kit (TaKaRa, Dalian, China). A SYBR Premix Ex Taq Kit (TaKaRa) and QuantStudio 6 Flex Real-Time PCR System (Applied Biosystems, Waltham, USA) were used to assess cDNA amplifications. Data were analyzed using the delta-delta cycle time (CT) method. All primers were designed with Primer-BLAST online (https://www.ncbi.nlm.nih.gov/tools/primer-blast) and obtained from Sigma-Aldrich. Primer sequences are provided in supplemental material Table S1. The average CT value of $\beta$-actin and GAPDH was used as the value for internal control. The assays were conducted in triplicate for each sample, and three experiments from separately generated samples were performed. 
3.7. Western Blot. Cells were incubated with cell lysis buffer (Cell Signaling, Danvers, USA) containing inhibitor cocktail of protease and phosphatase (Sigma-Aldrich) on ice for $30 \mathrm{~min}$. The protein sample $(25-40 \mu \mathrm{g})$ was run on $6 \%$, $10 \%$, or $15 \%$ Tris-glycine gels, transferred to polyvinylidene fluoride (PVDF) membrane, blocked in 5\% nonfat dry milk at room temperature (RT) for $2 \mathrm{~h}$, and incubated with the primary antibody at $4^{\circ} \mathrm{C}$ overnight and secondary antibody at RT for $1 \mathrm{~h}$. Membranes were developed with electrochemiluminescence (Tanon, Shanghai, China) and subsequently autoradiographied (Tanon). Quantification of the results adjusted to internal reference protein ( $\beta$-actin) was performed by ImageJ (Standard Edition, Bethesda, USA). Primary antibodies for phospho-mTOR (\#s6448, 1:1000), mTOR (\#2983P, 1:1000), phospho-P70S6K (\#9234, $1: 1000)$, RAPTOR (\#2280, 1:1500), P70S6K (\#2708, $1: 1000)$, and LAMP2 (\#49067, $1: 1000)$ were from Cell Signaling Technology. Primary antibodies for LC3 (\#121351-AP, 1:1000), p62/SQSTM1 (\#18420-1-AP, 1:10000), LAMP1 (\#21997-1-AP, 1:1000), and BECN1 (\#11306-1AP, $1: 1000)$ were from Proteintech Group (Wuhan, China). Primary antibodies for NRF2 (\#SC13032, $1: 500)$ and $\beta$-actin (\#SC1616, 1:5000) were from Santa Cruz Biotechnology (Santa Cruz, USA). Secondary antibodies were from Thermo Fisher Scientific.

3.8. Intracellular ROS Measurement. ROS levels were measured by flow cytometry using 5-(and-6)-chloromethyl-2', $7^{\prime}$-dichlorodihydrofluorescein diacetate, acetyl ester (CMH2DCFDA) (Thermo Fisher Scientific). Briefly, cells in each group were washed with PBS and incubated with $5 \mu \mathrm{M}$ of CM-H2DCFDA at RM in dark for $30 \mathrm{~min}$. The fluorescence of dichlorofluorescein was measured using Canto II flow cytometry (Becton Dickinson, San Jose, USA) with an excitation wavelength of $488 \mathrm{~nm}$ and emission wavelength of $525 \mathrm{~nm}$.

3.9. Autophagosome-Lysosome Fusion Detection. HaCaT cells were incubated with HBLV-mRFP-GFP-LC3 adenovirus (Hanhbio, Shanghai, China) for $24 \mathrm{~h}$ and screened with puromycin. The transduced cells were cultured in glass bottom cell culture dishes (NEST, Wuxi, China) and treated with $100 \mathrm{nM}$ of sodium arsenite for $4 \mathrm{~h}$ or $30 \mu \mathrm{M}$ of CQ for $6 \mathrm{~h}$. Pictures were acquired with $\mathrm{AI}^{+}$confocal microscopy (Nikon, Tokyo, Japan).

3.10. Statistical Analysis. All statistical analyses were performed by using GraphPad Prism 5 software (La Jolla, USA). For comparison between two groups, a $t$-test was performed. For comparison among multiple groups, one-way ANOVA with Tukey's multiple comparison test or two-way ANOVA with the Bonferroni post hoc test was performed. $p<0.05$ was considered significant. Data were expressed as mean \pm standard deviation (SD). Each experiment was independently repeated for at least three times.

\section{Discussion}

Environmental arsenic exposure has been known as a risk factor for skin cancer according to a number of epidemio- logical studies $[13,38,39]$. So, it is important to elucidate the intracellular target in response to arsenic at low, environmentally relevant doses. Arsenic is well known to increase intracellular ROS levels when the exposure dose is high [40]. However, at a relatively low dose, arsenic may not significantly increase ROS levels. When human fibroblast cells were exposed to $500 \mathrm{nM}$ of arsenite for $24 \mathrm{~h}$, ROS levels significantly decreased compared with control due to induction of stress-responsive genes [41]. In the present study, treatment with $100 \mathrm{nM}$ of arsenite did not significantly change ROS levels within $24 \mathrm{~h}$ (data not shown), but decreased ROS levels in the long term with enhanced p62NRF2 loop. Similarly, acute exposure to arsenite ( $2 \mathrm{~h}$ or $4 \mathrm{~h}$ ) below $10 \mu \mathrm{M}$ did not alter intracellular ROS amount in various cell lines, as detected with the same method in the present study or even with a more sensitive ROS detection method (electron paramagnetic resonance spectroscopy) $[20,26]$. In this scenario, arsenic does not appear to activate NRF2 via excessive generation of ROS, though the subtle ROS changes beyond sensitivity of the detection method cannot be excluded. It has been demonstrated that arsenic does not activate NRF2 in the traditional Keap1C151-depedent manner [42], which is common for transient NRF2 activation by sepharophone or tBHQ [20]. Earlier studies have established a noncanonical pathway for NRF2 activation mediated by p62 in arsenic-exposed cells [17, 20-22, 43]. Our data provide further evidence that ROS-independent noncanonical NRF2 activation may be involved in carcinogenesis caused by the environmentally relevant dose of arsenite.

Clearly, NRF2 protects cells from harmful effects of electrophilic and oxidative stressors [18]. It is considered that some NRF2 inducers, such as natural small molecules and food antioxidants, can reduce the risk of cancer. This concept is further verified in rodent experiments. Nrf2-deficient mice are more susceptible to chemical carcinogens [44, 45]. Although a transient increase in NRF2 levels is able to achieve protective antioxidant effects, constitutive NRF2 activation is very common in many epithelial cancers. In vivo study found an unexpected tumor-promoting role of NRF2 during early stage of skin tumorigenesis that was induced by virus [46]. NRF2 and its downstream genes were activated in the major precancerous human skin lesion [46]. Meanwhile, NRF2 overactivation is indicated to promote tumorigenesis in the liver of mice with loss of hepatic autophagy [47] or diethylnitrosamine administration [48]. Constitutive NRF2 activation promotes cancer initiation by conferring keratinocyte survival advantage (such as antiapoptosis) in adverse conditions [38, 49], as well as protumorigenic metabolic reprogramming toward anabolic glucose metabolism via the pentose phosphate pathway $[46,48]$. The drug detoxifying function may sometimes mask the oncogenic role of NRF2 in cases of chemical carcinogenesis. The present study provides a direct proof that inhibiting Nrf2 expression during long-term exposure to a low-level arsenite prevents from malignant transformation. Thus, the role of NRF2 in homeostatic response and in the pathogenesis of cancer is more complex than expected from the basic concepts.

The oncogenic role of p62 has been reported in several cancers [12-14], including in the skin [15]. Silencing p62 
weakens malignant phenotypes of arsenite-transformed human lung bronchial epithelial BEAS-2B cells and human keratinocyte $\mathrm{HaCaT}$ cells, such as proliferation, migration, and clonogenicity $[25,43]$. It is suggested that arsenic induces p62 accumulation due to disrupted autophagy. Once phosphorylated, p62 competes with NRF2 for binding to Keap1 [19], resulting in stabilization of NRF2 protein and subsequent activation of NRF2 downstream genes. Furthermore, p62 controls autophagy-induced degradation of Keap1 $[50,51]$ and is transcriptionally regulated by NRF2, thus forming a positive feedback loop with the NRF2 pathway. In the present study, we observed the augmented p62-NRF2 feedback loop in the arsenite-transformed keratinocyte model. The data suggest that protein degradation contributes to p62 protein accumulation in arsenite-exposed cells. This is consistent with the previous report that increased p62 mRNA level is insufficient for p62 protein aggravation, because the determinant factor of p62 protein level is autophagosomal-lysosomal proteolysis [52]. Upstream signaling of autophagy was also determined in this study. Activation of the mTORC1 pathway was observed in As-TM cells but not in acute arsenic-exposed cells (data not shown), which may be attributed to p62 accumulation $[52,53]$. Data from acute exposure also suggest that arsenite inhibits autophagy efflux by interfering lysosome dysfunction, such as decreased expression of the key lysosome membrane proteins, LAMP1 and LAMP2 $[54,55]$. The lysosome is a potential target organelle for arsenite toxicity and should be investigated in the future. Though alteration in response to acute arsenic exposure may not fully reflect mechanism underlying chronic exposure, determining the acute cellular response will greatly enhance our understanding of the early stages of arsenic carcinogenesis.

In summary, we have demonstrated that p62 accumulation resulting from inhibition of autophagic flux forms a positive feedback loop with the master regulator of antioxidative defense, NRF2, in response to the environmentally relevant dose of arsenite. Intervention of this loop may have significance in prophylactic strategy of arsenite-induced skin cancer and probably have implications in other arsenic-related cancers.

\section{Data Availability}

The data used to support the findings of this study are included within the article.

\section{Conflicts of Interest}

No potential conflicts of interest were disclosed.

\section{Authors' Contributions}

Xiafang $\mathrm{Wu}$ and $\mathrm{Ru}$ Sun contributed equally to this work.

\section{Acknowledgments}

This work was supported by the National Natural Science Foundation of China (81573187 and 81302391), the Liaoning Revitalization Talents Program (XLYC1807225), and the Key R\&D Plan Guidance Project (to Y.X.) from the Department of Science and Technology of Liaoning Province, China.

\section{Supplementary Materials}

Table S1: genes and primers for real-time RT-PCR. (Supplementary Materials)

\section{References}

[1] IARC Working Group on the Evaluation of Carcinogenic Risks to Humans, "Arsenic, metals, fibres, and dusts," IARC Monographs on the Evaluation of Carcinogenic Risks to Humans, vol. 100, pp. 11-465, 2012.

[2] L. C. Platanias, "Biological responses to arsenic compounds," The Journal of Biological Chemistry, vol. 284, no. 28, pp. 18583-18587, 2009.

[3] G. Alain, J. Tousignant, and E. Rozenfarb, "Chronic arsenic toxicity," International Journal of Dermatology, vol. 32, no. 12, pp. 899-901, 1993.

[4] IARC Working Group on the Evaluation of Carcinogenic Risks to Humans, "Some drinking-water disinfectants and contaminants, including arsenic. Monographs on chloramine, chloral and chloral hydrate, dichloroacetic acid, trichloroacetic acid and 3-chloro-4-(dichloromethyl)-5-hydroxy-2(5H)-furanone," IARC Monographs on the Evaluation of Carcinogenic Risks to Humans, vol. 84, pp. 269-477, 2004.

[5] National Research Council Subcommittee to Update the Arsenic in Drinking Water R, Arsenic in Drinking Water: 2001 Update, National Academies Press (US) Copyright 2001 by the National Academy of Sciences, Washington (DC), 2001, All rights reserved.

[6] K. Degenhardt, R. Mathew, B. Beaudoin et al., "Autophagy promotes tumor cell survival and restricts necrosis, inflammation, and tumorigenesis," Cancer Cell, vol. 10, no. 1, pp. 51-64, 2006.

[7] E. White, C. Karp, A. M. Strohecker, Y. Guo, and R. Mathew, "Role of autophagy in suppression of inflammation and cancer," Current Opinion in Cell Biology, vol. 22, no. 2, pp. 212-217, 2010.

[8] M. D. Rybstein, J. M. Bravo-San Pedro, G. Kroemer, and L. Galluzzi, "The autophagic network and cancer," Nature Cell Biology, vol. 20, no. 3, pp. 243-251, 2018.

[9] R. K. Amaravadi and C. B. Thompson, "The roles of therapyinduced autophagy and necrosis in cancer treatment," Clinical Cancer Research: An Official Journal of the American Association for Cancer Research, vol. 13, no. 24, pp. 7271-7279, 2007.

[10] S. Rao, L. Tortola, T. Perlot et al., "A dual role for autophagy in a murine model of lung cancer," Nature Communications, vol. 5, no. 1, article 3056, 2014.

[11] V. Rogov, V. Dotsch, T. Johansen, and V. Kirkin, "Interactions between autophagy receptors and ubiquitin-like proteins form the molecular basis for selective autophagy," Molecular Cell, vol. 53, no. 2, pp. 167-178, 2014.

[12] H. G. R. Thompson, J. W. Harris, B. J. Wold, F. Lin, and J. P. Brody, "p62 overexpression in breast tumors and regulation by prostate-derived Ets factor in breast cancer cells," Oncogene, vol. 22, no. 15, pp. 2322-2333, 2003.

[13] D. Inoue, T. Suzuki, Y. Mitsuishi et al., "Accumulation of p62/SQSTM1 is associated with poor prognosis in patients with lung adenocarcinoma," Cancer Science, vol. 103, no. 4, pp. 760-766, 2012.

[14] A. Umemura, F. He, K. Taniguchi et al., "p62, upregulated during preneoplasia, induces hepatocellular carcinogenesis by 
maintaining survival of stressed HCC-initiating cells," Cancer Cell, vol. 29, no. 6, pp. 935-948, 2016.

[15] L. Qiang, B. Zhao, M. Ming et al., "Regulation of cell proliferation and migration by $\mathrm{p} 62$ through stabilization of Twist 1 ," Proceedings of the National Academy of Sciences of the United States of America, vol. 111, no. 25, pp. 9241-9246, 2014.

[16] J. Moscat and M. T. Diaz-Meco, "p62 at the crossroads of autophagy, apoptosis, and cancer," Cell, vol. 137, no. 6, pp. 1001-1004, 2009.

[17] A. Jain, T. Lamark, E. Sjøttem et al., “p62/SQSTM1 is a target gene for transcription factor NRF2 and creates a positive feedback loop by inducing antioxidant response element-driven gene transcription," The Journal of Biological Chemistry, vol. 285, no. 29, pp. 22576-22591, 2010.

[18] M. Yamamoto, T. W. Kensler, and H. Motohashi, "The KEAP1-NRF2 system: a thiol-based sensor-effector apparatus for maintaining redox homeostasis," Physiological Reviews, vol. 98, no. 3, pp. 1169-1203, 2018.

[19] M. Komatsu, H. Kurokawa, S. Waguri et al., "The selective autophagy substrate p62 activates the stress responsive transcription factor Nrf 2 through inactivation of Keap 1," Nature Cell Biology, vol. 12, no. 3, pp. 213-223, 2010.

[20] A. Lau, X. J. Wang, F. Zhao et al., “A noncanonical mechanism of Nrf 2 activation by autophagy deficiency: direct interaction between Keap 1 and p62," Molecular and Cellular Biology, vol. 30, no. 13, pp. 3275-3285, 2010.

[21] J. Pi, B. A. Diwan, Y. Sun et al., "Arsenic-induced malignant transformation of human keratinocytes: involvement of Nrf 2," Free Radical Biology \& Medicine, vol. 45, no. 5, pp. 651658, 2008.

[22] A. Lau, Y. Zheng, S. Tao et al., "Arsenic inhibits autophagic flux, activating the Nrf2-Keap1 pathway in a p62-dependent manner," Molecular and Cellular Biology, vol. 33, no. 12, pp. 2436-2446, 2013.

[23] Y. Qi, M. Zhang, H. Li et al., “Autophagy inhibition by sustained overproduction of IL6 contributes to arsenic carcinogenesis," Cancer Research, vol. 74, no. 14, pp. 3740-3752, 2014.

[24] X. Liu, M. Ling, C. Chen et al., "Impaired autophagic flux and p62-mediated EMT are involved in arsenite-induced transformation of L-02 cells," Toxicology and Applied Pharmacology, vol. 334, pp. 75-87, 2017.

[25] P. Shah, E. Trinh, L. Qiang et al., "Arsenic induces p62 expression to form a positive feedback loop with Nrf2 in human epidermal keratinocytes: implications for preventing arsenicinduced skin cancer," Molecules, vol. 22, no. 2, p. 194, 2017.

[26] M. Dodson, M. R. de la Vega, B. Harder et al., "Low-level arsenic causes proteotoxic stress and not oxidative stress," Toxicology and Applied Pharmacology, vol. 341, pp. 106-113, 2018.

[27] A. Leone, U. Flatow, C. R. King et al., "Reduced tumor incidence, metastatic potential, and cytokine responsiveness of nm23-transfected melanoma cells," Cell, vol. 65, no. 1, pp. 25-35, 1991.

[28] M. Valko, H. Morris, and M. T. Cronin, "Metals, toxicity and oxidative stress," Current Medicinal Chemistry, vol. 12, no. 10, pp. 1161-1208, 2005.

[29] G. Bjørkøy, T. Lamark, S. Pankiv, A. Øvervatn, A. Brech, and T. Johansen, "Chapter 12 Monitoring Autophagic Degradation of p62/SQSTM1," Methods in Enzymology, vol. 452, pp. 181197, 2009.

[30] N. Mizushima and T. Yoshimori, "How to interpret LC3 immunoblotting," Autophagy, vol. 3, no. 6, pp. 542-545, 2007.
[31] T. Shintani and D. J. Klionsky, "Autophagy in health and disease: a double-edged sword," Science, vol. 306, no. 5698, pp. 990-995, 2004.

[32] M. Pajares, A. I. Rojo, E. Arias, A. Diaz-Carretero, A. M. Cuervo, and A. Cuadrado, "Transcription factor NFE2L2/NRF2 modulates chaperone-mediated autophagy through the regulation of LAMP2A," Autophagy, vol. 14, no. 8, pp. 13101322, 2018.

[33] J. Pi, Y. He, C. Bortner et al., "Low level, long-term inorganic arsenite exposure causes generalized resistance to apoptosis in cultured human keratinocytes: potential role in skin co-carcinogenesis," International Journal of Cancer, vol. 116, no. 1, pp. 20-26, 2005.

[34] R. Zhao, Y. Hou, Q. Zhang et al., "Cross-regulations among NRFs and KEAP1 and effects of their silencing on arsenicinduced antioxidant response and cytotoxicity in human keratinocytes," Environmental Health Perspectives, vol. 120, no. 4, pp. 583-589, 2012.

[35] R. Zhao, B. Yang, L. Wang et al., "Curcumin protects human keratinocytes against inorganic arsenite-induced acute cytotoxicity through an NRF2-dependent mechanism," Oxidative Medicine and Cellular Longevity, vol. 2013, Article ID 412576, 11 pages, 2013.

[36] N. Ke, X. Wang, X. Xu, and Y. A. Abassi, "The xCELLigence system for real-time and label-free monitoring of cell viability," in Mammalian Cell Viability, M. Stoddart, Ed., vol. 740 of Methods in Molecular Biology, , pp. 33-43, Humana Press, 2011.

[37] Y. Xu, E. J. Tokar, Y. Sun, and M. P. Waalkes, “Arsenic-transformed malignant prostate epithelia can convert noncontiguous normal stem cells into an oncogenic phenotype," Environmental Health Perspectives, vol. 120, no. 6, pp. 865871, 2012.

[38] P. Ghosh, M. Banerjee, S. de Chaudhuri et al., "Comparison of health effects between individuals with and without skin lesions in the population exposed to arsenic through drinking water in West Bengal, India," Journal of Exposure Science \& Environmental Epidemiology, vol. 17, no. 3, pp. 215-223, 2007.

[39] W. P. Tseng, H. M. Chu, S. W. How, J. M. Fong, C. S. Lin, and S. Yeh, "Prevalence of skin cancer in an endemic area of chronic arsenicism in Taiwan," JNCI: Journal of the National Cancer Institute, vol. 40, no. 3, pp. 453-463, 1968.

[40] D. H. Edwards, Y. Li, D. C. Ellinsworth, and T. M. Griffith, "The effect of inorganic arsenic on endothelium-dependent relaxation: role of NADPH oxidase and hydrogen peroxide," Toxicology, vol. 306, pp. 50-58, 2013.

[41] E. T. Snow, P. Sykora, T. Durham, and C. Klein, "Arsenic, mode of action at biologically plausible low doses: what are the implications for low dose cancer risk?," Toxicology and Applied Pharmacology, vol. 207, no. 2, Supplement, pp. 557564, 2005.

[42] D. D. Zhang and M. Hannink, "Distinct cysteine residues in Keap1 are required for Keap1-dependent ubiquitination of Nrf2 and for stabilization of Nrf2 by chemopreventive agents and oxidative stress," Molecular and Cellular Biology, vol. 23, no. 22, pp. 8137-8151, 2003.

[43] Y. O. Son, P. Pratheeshkumar, R. V. Roy et al., "Antioncogenic and oncogenic properties of Nrf2 in arsenic-induced carcinogenesis," The Journal of Biological Chemistry, vol. 290, no. 45, pp. 27090-27100, 2015.

[44] M. Ramos-Gomez, M. K. Kwak, P. M. Dolan et al., "Sensitivity to carcinogenesis is increased and chemoprotective efficacy of 
enzyme inducers is lost in $n r f 2$ transcription factor-deficient mice," Proceedings of the National Academy of Sciences of the United States of America, vol. 98, no. 6, pp. 34103415, 2001.

[45] M. Ramos-Gomez, P. M. Dolan, K. Itoh, M. Yamamoto, and T. W. Kensler, "Interactive effects of nrf2 genotype and oltipraz on benzo[a]pyrene-DNA adducts and tumor yield in mice," Carcinogenesis, vol. 24, no. 3, pp. 461-467, 2003.

[46] F. Rolfs, M. Huber, A. Kuehne et al., "Nrf2 activation promotes keratinocyte survival during early skin carcinogenesis via metabolic alterations," Cancer Research, vol. 75, no. 22, pp. 48174829, 2015.

[47] H. M. Ni, B. L. Woolbright, J. Williams et al., "Nrf2 promotes the development of fibrosis and tumorigenesis in mice with defective hepatic autophagy," Journal of Hepatology, vol. 61, no. 3, pp. 617-625, 2014.

[48] H. K. C. Ngo, D. H. Kim, Y. N. Cha, H. K. Na, and Y. J. Surh, "Nrf2 mutagenic activation drives hepatocarcinogenesis," Cancer Research, vol. 77, no. 18, pp. 4797-4808, 2017.

[49] J. Fu, C. G. Woods, E. Yehuda-Shnaidman et al., "Low-level arsenic impairs glucose-stimulated insulin secretion in pancreatic beta cells: involvement of cellular adaptive response to oxidative stress," Environmental Health Perspectives, vol. 118, no. 6, pp. 864-870, 2010.

[50] I. M. Copple, A. Lister, A. D. Obeng et al., "Physical and functional interaction of sequestosome 1 with Keap1 regulates the Keap1-Nrf2 cell defense pathway," The Journal of Biological Chemistry, vol. 285, no. 22, pp. 16782-16788, 2010.

[51] K. Taguchi, N. Fujikawa, M. Komatsu et al., "Keap1 degradation by autophagy for the maintenance of redox homeostasis," Proceedings of the National Academy of Sciences of the United States of America, vol. 109, no. 34, pp. 13561-13566, 2012.

[52] M. Komatsu, S. Kageyama, and Y. Ichimura, "p62/SQSTM1/A170: physiology and pathology," Pharmacological Research, vol. 66, no. 6, pp. 457-462, 2012.

[53] J. F. Linares, A. Duran, M. Reina-Campos et al., "Amino acid activation of mTORC1 by a PB1-domain-driven kinase complex cascade," Cell Reports, vol. 12, no. 8, pp. 1339-1352, 2015.

[54] E. L. Eskelinen, "Roles of LAMP-1 and LAMP-2 in lysosome biogenesis and autophagy," Molecular Aspects of Medicine, vol. 27, no. 5-6, pp. 495-502, 2006.

[55] A. R. Issa, J. Sun, C. Petitgas et al., "The lysosomal membrane protein LAMP2A promotes autophagic flux and prevents SNCA-induced Parkinson disease-like symptoms in the Drosophila brain," Autophagy, vol. 14, no. 11, pp. 1898-1910, 2018. 


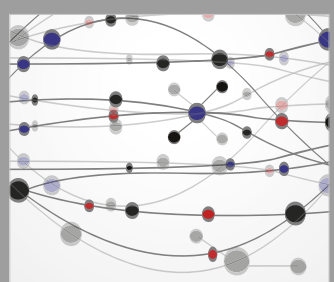

The Scientific World Journal
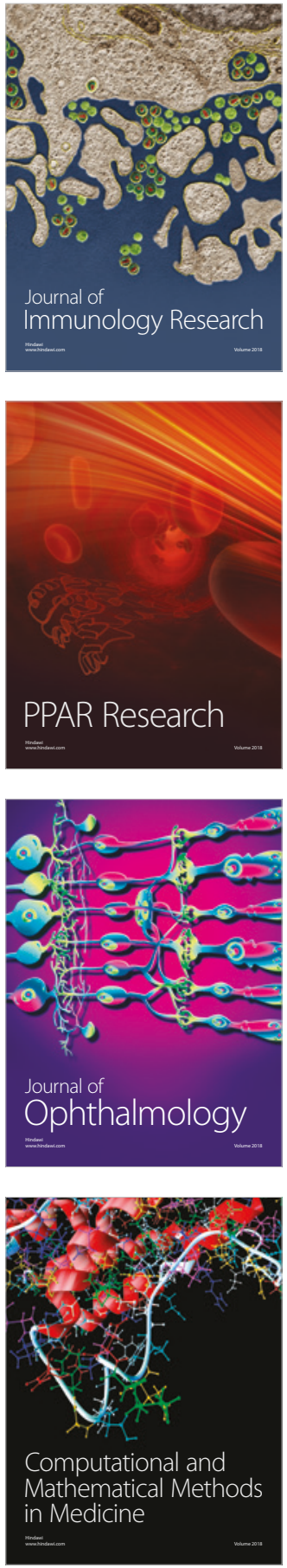

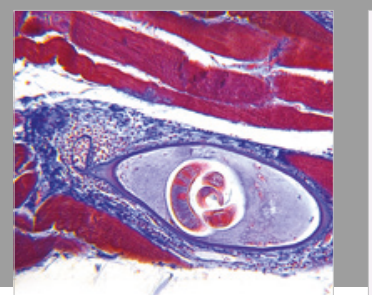

Gastroenterology Research and Practice

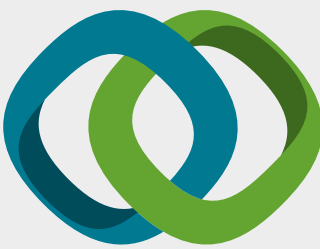

\section{Hindawi}

Submit your manuscripts at

www.hindawi.com
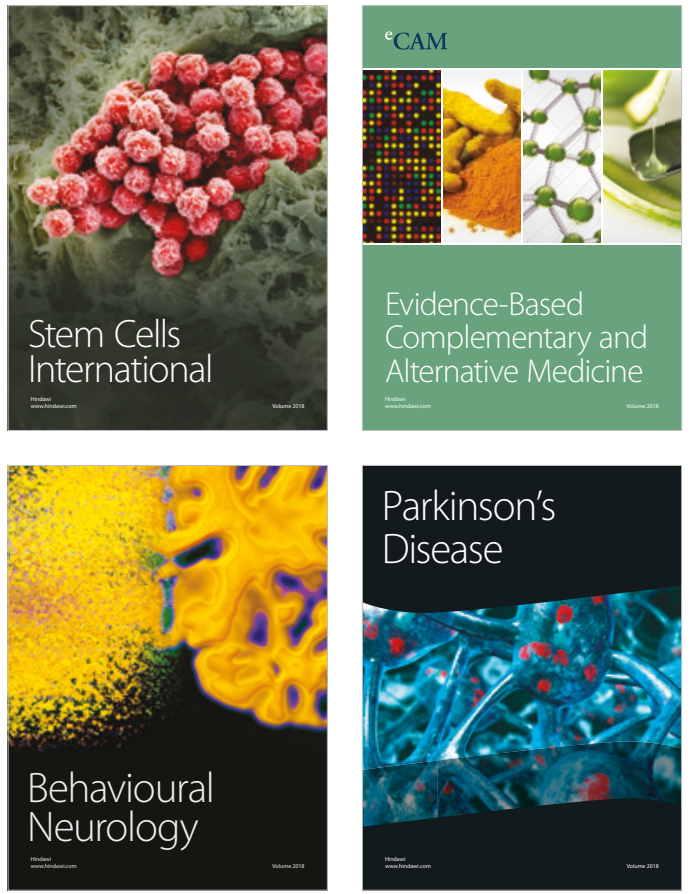

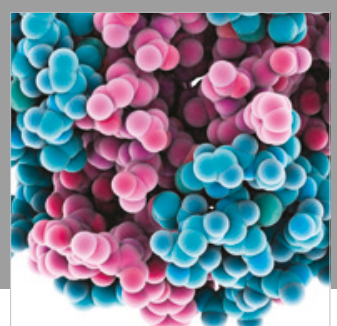

ournal of

Diabetes Research

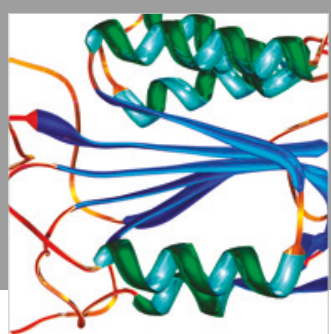

Disease Markers
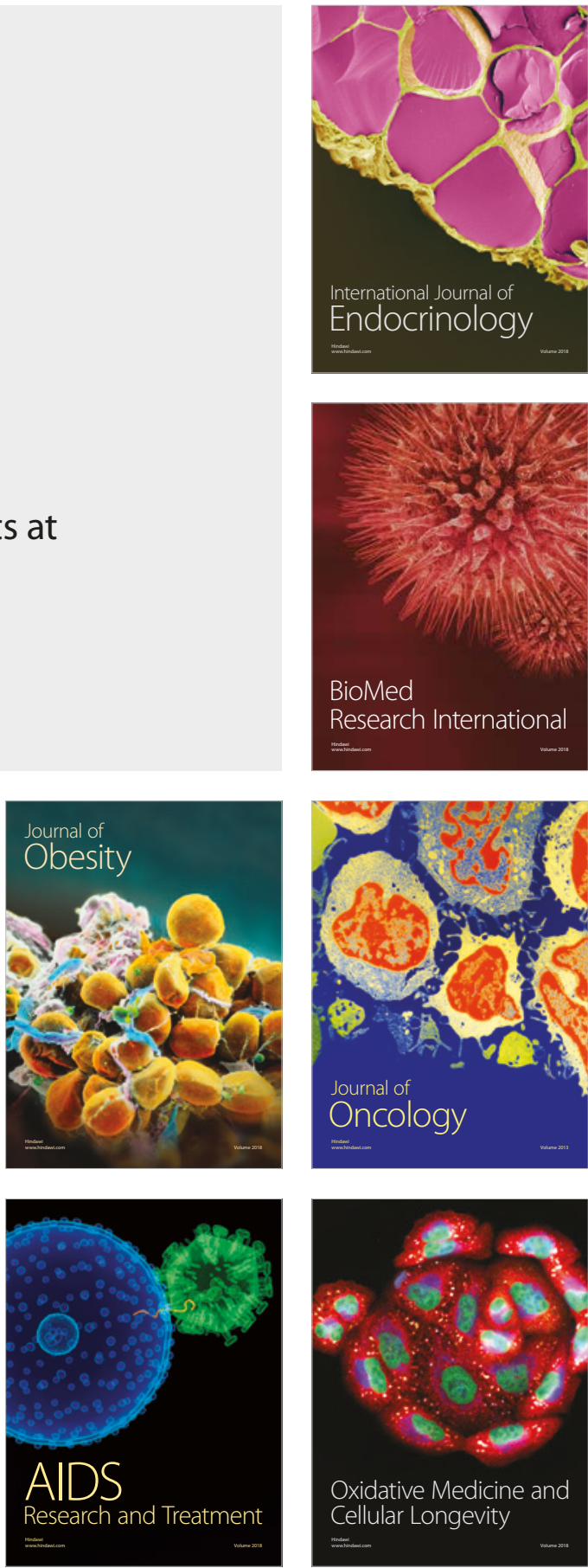